\title{
Trayectorias y articulaciones de una sanadora kaingang en Santa Catarina, Sur de Brasil
}

\author{
ARI GHIGGI JUNIOR
}

\begin{abstract}
En este texto se reflexiona sobre el pluralismo médico a partir de un estudio de caso sobre la agencia de una indígena kaingang orientada a la oferta de prácticas terapéuticas en la región Oeste de Santa Catarina, en el Sur de Brasil. Su trayectoria de vida pone en evidencia su contacto con una diversidad de actores y tradiciones médicas que deriva en la utilización de un conjunto heterogéneo de prácticas para diagnosticar y tratar diversas enfermedades. El resultado es una actividad extremadamente dinámica, marcada por el hibridismo característico de una situación específica de intermedicalidad. La oferta de estos tratamientos para las poblaciones vecinas implica relaciones de intercambio y sociabilidad que se traducen en ingresos monetarios como estrategia de supervivencia.
\end{abstract}

PALABRAS CLAVE: indios kaingang, intermedicalidad, agencia, relaciones interétnicas, etnografía

Trajectories and Articulations of a Kaingang Healer in Santa Catarina, Southern Brazil

This text is a reflection on medical pluralism based on ethnography around the agencies oriented towards the offer of therapeutic practices by an indigenous Kaingang in the western region of Santa Catarina, southern Brazil. His life trajectory shows the contact with a diversity of actors and medical traditions that result in a set of practices used in diagnoses and in action against the most diverse diseases. The result is an extremely dynamic activity, marked by the hybridism in a specific situation of intermedicality. The offer of these treatments to the neighboring populations aims for exchange relations and

ARI GHIGGI JUNIOR Universidade Federal de Santa Catarina,

Florianópolis, Brasil ari.ghiggi@gmail.com sociability that results in monetary income as a survival strategy.

KEYWORDS: Kaingang indigenous people, intermedicality, agency, interethnic relations, ethnography 


\section{Introducción}

n este artículo se explora el pluralismo médico a partir del estudio de caso de

la agencia de Luciana, una indígena kaingang habitante de la Tierra Indígena Xapecó (TIX), en el Oeste de Santa Catarina. Su praxis emergente, heterogénea y dinámica está orientada a la oferta terapéutica, escapa de los estereotipos de la "medicina tradicional" intacta, atraviesa relaciones interétnicas e interculturales, e ilustra las posibilidades de empoderamiento de los indígenas en el contexto regional, en especial en el campo de la atención a la salud.

Los kaingang pertenecen al tronco lingüístico macro-jê y hoy en día representan la tercera población indígena más grande de Brasil, que supera los 37000 individuos (IBGE, 2012). Desde el estado de São Paulo hasta Rio Grande do Sul, los kaingang se sitúan en 32 territorios indígenas, de los cuales siete se ubican en el Oeste del estado de Santa Catarina. Las presiones provocadas por varios frentes económicos de ocupación y colonización desde el siglo XIX resultaron en la reducción de la TIX a 16283 hectáreas (ISA, 2015), en las que hoy se establecen 13 aldeas, con una población de casi 6000 habitantes (Fundação Nacional do Índio, citado en ISA, 2015). La aldea sede, que representa el centro de la TIX, es la más poblada, con cerca de 1500 habitantes. Además de las instituciones burocráticas oficiales, como la escuela de enseñanza básica y el puesto de salud, llama la atención la presencia de una iglesia católica y más de diez evangélicas. ${ }^{1}$

$1 \quad$ El contacto inicial de los kaingang de la región Oeste de Santa Catarina con las religiones cristianas no está datado con exactitud, pero se sabe que ocurrió en los siglos XVIII y XIX, y que estuvo mediado por padres capuchinos provenientes del estado de Paraná y por las relaciones con poblaciones no indígenas y sus prácticas católicas (Almeida, 1998; Oliveira, 1996). Durante el siglo xx también actuaron en la región otros agentes del catolicismo oficial. Según Almeida (1998), a partir de la década de 1940 comenzaron las prácticas de adeptos y predicadores de iglesias protestantes. A finales de la década de 1970, con más precisión de la de 1980, proliferaron las iglesias pentecostales. Quien visite hoy alguna de las aldeas de la tix notará la gran cantidad de iglesias y la relativa variedad de denominaciones que existen: O Brasil para Cristo, Só o Senhor é Deus, Rei da Glória, Noiva de Jesus, Rosa de Saron, Deus é Amor, Unindo-se pela Fé y Visão Missionária. 
La TIX se ubica en los municipios de Ipuaçu y Entre Rios, a una distancia de más o menos $30 \mathrm{~km}$ de la ciudad de Xanxerê, a $25 \mathrm{~km}$ de la ciudad de Abelardo Luz, a $70 \mathrm{~km}$ de la ciudad de Xapecó y a $540 \mathrm{~km}$ de Florianópolis, la capital del estado. La proximidad respecto a los centros urbanos regionales se asocia a las dinámicas de circulación de los indígenas por los municipios vecinos y de los no indígenas por el interior de la reserva. Vendedores de productos alimenticios y utensilios domésticos, profesionales de los sectores de educación y salud, agentes religiosos evangélicos o católicos, y parientes no indígenas que viven en los alrededores son algunos ejemplos de agentes externos que frecuentan las aldeas de manera cotidiana. Los indígenas, a su vez, se desplazan para visitar a sus familiares establecidos en la periferia de las ciudades vecinas y para acceder a las instituciones de salud del sector público, cuando es necesario. Para los pocos que poseen algún tipo de recurso financiero propio, hay un tránsito menos intenso por las instituciones particulares de educación superior.

En general, para la población indígena de la TIX, las ciudades son atractivas por la oferta de productos y bienes de consumo, como juguetes, ropa, utensilios domésticos, electrónicos, y principalmente, alimentos. Con esto quiero decir que la motivación primordial para la circulación de los indígenas por la región todavía se relaciona con estrategias de subsistencia ante la situación socioeconómica precarizada en la que viven. Pocos se alimentan con lo que plantan en huertas de pequeña escala. Los alimentos básicos, como la carne de pollo, el frijol y el arroz, todavía se adquieren fuera de la aldea con recursos particulares. Una parte considerable de la población recibe ayudas gubernamentales, como el subsidio Bolsa Familia o la jubilación, y otra, menor, trabaja en el puesto de salud o en las escuelas. Para la gran mayoría, los recursos provienen de trabajos subalternos realizados para los vecinos no indígenas. Ésta es una de las causas principales de la presencia indígena en las ciudades del entorno, en las que laboran como albañiles o rozadores, en el caso de los hombres, y como empleadas domésticas o niñeras, en el caso de las mujeres. En la actualidad, el número de indígenas que vende su fuerza de trabajo en frigoríficos con gran escala de producción de alimentos de cerdo y aves es considerable. Los indígenas también se contratan para trabajar en cultivos estacionales de manzana o maíz en otras localidades del estado. Algunos se aventuran en viajes más largos y se establecen con sus familias en la periferia de ciudades grandes, como Florianópolis, con empleos que exigen poco o ningún nivel de escolaridad. Otros buscan sustento en la administración de puntos comerciales informales en la TIX, las llamadas bodegas, donde revenden dulces, paletas, gaseosas o productos alimenticios más urgentes que se adquieren en las ciudades vecinas. La artesanía es una fuente de ingresos sólo para una minoría de familias que se desplaza a diario a las ciudades vecinas para vender canastos, arcos y flechas. La presencia indígena en los municipios vecinos está permeada por negociaciones en torno a la tolerancia: por un lado, las poblaciones no indígenas a menudo los califican de sucios, borrachos y vagabundos, pero se interesan en su fuerza de trabajo o los ven como posibles clientes de sus establecimientos comerciales; y por el otro, los kaingang se quejan constantemente de la avaricia de los blancos y los prejuicios que los afectan.

La propuesta de este estudio apunta a la comprensión del pluralismo médico como situación de intermedicalidad entre indígenas brasileños, es decir, como contexto dinámico, caracterizado por sus discontinuidades y transformaciones. Sin perder de vista una actitud cautelosa en relación con la ahistoricidad de los procesos de salud/enfermedad/ atención y las relaciones de hegemonía y subalternidad subyacentes, la visión crítica que se expone evita una lectura coleccionista que esencializa sistemas culturales, para encarar la heterogeneidad de prácticas terapéuticas en un campo emergente 
(Frankenberg, 1980; Baer, Singer y Johnsen, 1986; Singer, 1990; Seppilli y Otegui, 2005; Menéndez, 2009; Langdon y Cardoso, 2015).

Pensar en el aspecto de la hegemonía frente a la emergencia de formas de resistencia, de actuaciones creativas, no conformistas y transformadoras de los agentes subalternos nos remite a la noción de agencia — agency — como la "capacidad de actuar" de los sujetos. Según Ortner (2007), la cultura construye actores sociales particulares y la vivencia práctica reproduce y transforma sus valores, una relación dinámica entre las prácticas de personas reales y las estructuras de la sociedad, la cultura y la historia. La noción de proyecto califica la agencia como acción intencionada, activa, que de alguna forma se diferencia de las prácticas de rutina. La agencia se sitúa en varios regímenes de poder, o sea, tiene que ver con la resistencia o dominación, la estabilización o desestabilización de las relaciones de poder.

La valoración de la agencia nos lleva a considerar el pluralismo médico como contexto terapéutico heterogéneo, resultado de las negociaciones entre agentes para el desarrollo de proyectos en medio de regímenes de poder. Greene (1998) esclarece estas ideas cuando apunta a la categoría de intermedicalidad para reflexionar sobre el encuentro colonial en el campo de la atención a la salud. Para ella, la agencia remite a la comprensión de los sistemas médicos como formas híbridas, dinámicas y emergentes, cuyo desenvolvimiento sintetiza e incorpora elementos, prácticas y cosmologías diversas. Follér (2004) denomina zonas de contacto a aquellos espacios en los que se constituyen procesos de diálogo entre los modos de conocimiento sobre salud y enfermedad, presentes en un ambiente sociocultural determinado. Scopel, Dias-Scopel y Wiik resumen la definición del espacio de intermedicalidad como "el campo de actuación y de fuerzas producido por los diversos actores sociales, del que emergen saberes 'híbridos' volcados hacia el proceso de salud, enfermedad y atención, o sea, un espacio demarcado por negociaciones entre actores diversos" (2012: 175). Así, la intermedicalidad sería una zona fronteriza dada por la coexistencia de una variedad de tradiciones médicas, entre las cuales hay enfrentamientos, oposiciones, conflictos, reapropiaciones, resignificaciones y fusiones de elementos y técnicas.

El análisis que aquí se presenta tiene estos presupuestos como telón de fondo y es fruto de mi experiencia de trabajo de campo con los kaingang de la TIX desde 2003 (Ghiggi, 2006; 2010; Ghiggi y Langdon, 2013; 2014), en especial a partir de la investigación para la tesis de doctorado en antropología social, entre agosto de 2013 y febrero de 2015 (Ghiggi, 2015). ${ }^{2}$ En términos metodológicos, con esta etnografía se mapearon los recursos terapéuticos referenciales, como actores relevantes para los kaingang que habitan la TIX, a partir de los itinerarios terapéuticos recorridos por sujetos y grupos domésticos en el desarrollo de procesos de salud/ enfermedad/atención. De esta forma, fue posible percibir un contexto regional plural y heterogéneo, marcado por la presencia de diversas tradiciones médicas. Para tratar sus enfermedades, los indígenas recurrían a una multiplicidad de agentes: los vinculados a las iglesias evangélicas o el catolicismo popular, la Pastoral de Salud, los servicios e instituciones de salud del Estado, las farmacias en las ciudades vecinas, incluso los conocimientos formales de personas no indígenas.

Mi reflexión gira en torno a la agencia y otros aspectos de la biografía de una sanadora indígena kaingang, a quien he llamado Luciana, para comprender la emergencia de sus prácticas. Mi idea es

2

Agradezco el apoyo del Instituto Nacional de Ciência e Tecnologia Brasil Plural, de la Coordenação de Aperfeiçoamento de Pessoal de Nivel Superior y del Conselho Nacional de Desenvolvimento Científico e Tecnológico para la realización del doctorado y la investigación de campo, que obtuvo una calificación favorable de la Comissão Nacional de Ética em Pesquisa, núm. 256216. 
poner en evidencia los modos en que aprovecha los modelos terapéuticos presentes en la TIX para componer su propia práctica, en la cual ella es un referente terapéutico o una especialista tanto para indígenas como para no indígenas en la región.

\section{Intermedicalidad}

En este contexto, examinaremos la experiencia y trayectoria de Luciana, una mujer indígena de aproximadamente 60 años de edad. En 2012, vivía en la aldea sede con su hijo de casi 30 años de edad y dos nietos menores de diez años, en una casa de cemento pequeña, con dos habitaciones. En esa época, el hijo estaba desempleado y sobrevivía haciendo varios trabajos. La única renta segura que poseían era el dinero que Luciana recibía de su jubilación. Ella frecuentaba la iglesia evangélica Rey de la Gloria, en la aldea sede de la TIX. Las iglesias evangélicas se instalaron ahí sobre todo después de la década de 1970 (Almeida, 1998) y se relacionan con las prácticas de agentes religiosos, como pastores, presbíteros u obreros, sometidos a una estructura jerárquica burocratizada, con fuerte base institucional y organizada en congregaciones. El culto es la principal actividad de los creyentes en la TIX, un ritual que ocurre hasta cuatro veces por semana. Son momentos de consolidación de los lazos entre los fieles y entre éstos y la iglesia en la que se congregan.

Cuando Luciana aceptó a Jesús ${ }^{3}$ y se convirtió en creyente, ${ }^{4}$ empezó a seguir la doctrina con rigidez. ${ }^{5}$ Cabe mencionar que es hermana del pastor Mario, quien comanda esta congregación y necesita dar buen ejemplo. Luciana nació en la aldea Pinhalzinho y afirma poseer un don espiritual ${ }^{6}$ no usual entre los creyentes en general: el don de las hierbas medicinales. Como veremos, ella ejerce este don con vehemencia y espera con ello difundir la palabra de Dios y fortalecer el proselitismo evangélico.
Luciana asocia el comienzo de su trayectoria como sanadora a una experiencia de misterio, ${ }^{7}$ importante para explicar por qué se convirtió en un referente terapéutico en la localidad:

Yo trabajo con las hierbas medicinales. Fue Dios quien me dio ese don, ¿verdad? Al principio no le daba importancia. Yo tenía 18 años la primera vez que Dios empezó a mostrarme las hierbas. Siempre

3

"Aceptar a Jesús" es el término utilizado por los evangélicos para denominar el proceso de asistir a alguna iglesia de manera formal. Significa curarse, al seguir una moralidad que guía las relaciones sociales. Los procesos de salud, enfermedad y atención son piezas centrales en la estructuración y justificación de la praxis religiosa, en la que la idea de fondo es la batalla del bien contra el mal. También significa percibir la supremacía de Dios en la esfera secular.

$4 \quad$ Creyente es el modo en que los practicantes de la religiosidad evangélica se autoidentifican y son identificados en la localidad como pertenecientes al grupo de los evangélicos.

$5 \quad$ La doctrina se refiere a una serie de reglas que todos los creyentes deben seguir, que conciernen a aspectos de la corporalidad, como la utilización de vestimentas específicas - pantalones y camisas sociales para los hombres y faldas para las mujeres - y cortes de cabello -largo para las mujeres y corto con barba bien afeitada para los hombres-. También se relacionan con aspectos comportamentales y prohibiciones, como participar en juegos, bailes, cometer adulterio y consumir bebidas alcohólicas.

$6 \quad$ Los dones espirituales se asocian a la manifestación de Dios por medio del Espíritu Santo en el cuerpo-instrumento del agente religioso, para alcanzar algún tipo de intervención en la esfera secular. Los dones más observados en la TIX son revelación, palabra, visión, profetización, oración en lenguas y sanación. Estos dones se refieren a hechos específicos y elevan al agente a posiciones destacadas en la comunidad evangélica, y éste pasa a integrar y fortalecer la estructura jerárquica de su congregación.

7 El misterio es un enigma que se coloca ante un sujeto que todavía no cree que el camino correcto a seguir es el evangélico. Por lo general, se manifiesta como una crisis, cuya persistencia trae a la luz cuestiones existenciales profundas. Después de su resolución, la reinterpretación de los acontecimientos revela que la crisis era un mecanismo de Dios para conducir al sujeto hacia su destino de conversión a la religión evangélica. 
tenía ese sueño en que Dios me mostraba las cosas que iban a suceder. Yo tenía una enfermedad, Ari. Camila tiene diez años, hace unos nueve años que me empecé a enfermar, enfermar y me fui a la cama. No aguantaba más enferma. Y ahí dije así a Dios: "mire, si es para que yo haga lo que me está mostrando, entonces levánteme ahora de esta cama”. Ahí, en aquel momento, me levanté. Aquella noche Dios me mostró que yo tenía que hacer un remedio para la anemia, que iba a llegar una mujer muy enferma y que yo debía dejar listo aquel remedio, que a ella ya le estaba entrando leucemia en la sangre. Yo no conocía a la mujer. Ahí le dije a Salete: "voy a dejar este remedio. ¡Listo, Salete! Alguien que va a venir me va a necesitar hoy". Yo fui a la ciudad, fui al mercado. Cuando me fui, llegaron con la mujer enferma. Pero llegaron cargándola. A ella ya le estaba entrando la leucemia. Ella había ido a Xapecó, ya había ido a Florianópolis y ya la anemia le había avanzado. Entonces yo volví y les dije a ellos: "Dios me mostró que iban a traer a esa mujer". Una mujer dijo: “doña Luciana, la comida de ella hoy fue media cucharada de sopa, el caldito de papa". Yo le dije: "mire, ustedes van a llevar este remedio". Dejé una botella de dos litros con su hija. Y ella tomó y dije: "mire, ella va a dormir. Usted no se preocupe, ella llega y ella va a dormir. Se levantará a las diez de la noche. Ella se despierta. Si ella quiere bañarse, deje que se bañe, ella se va a levantar con hambre. Dejen un caldo listo, fuerte". Ella dijo: “¿ella va a pedir comida?”. "Confía en Dios", dije. De ahí empecé a orar. Dios me dio la oración ahí mismo. Oré y se fueron a casa. Llevaron el remedio a la mujer. Ella durmió y a las diez de la noche se levantó y dijo: "tengo hambre". Entonces la mujer ya había preparado la sopa, comió medio plato. Ya empezó a mejorar. Por la mañana temprano ya llegó un carro allí para buscarme para verla. Después de eso, aquella blanca ${ }^{8}$ comenzó a decir que yo hacía remedio, que ella ya estaba casi muerta, que mi remedio la había curado a ella, ¿sabe?

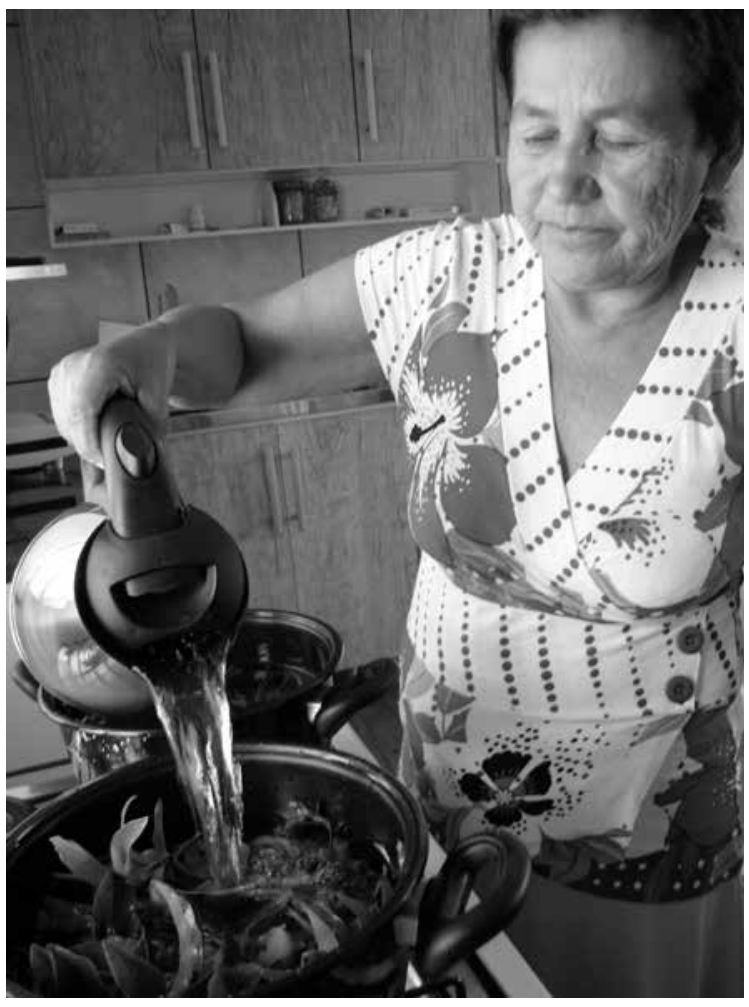

ARI GHIGGI JUNIOR • Sanadora prepara infusión con "remedios del monte".

Entonces la gente empezó a venir, ¡mi Dios del cielo! Yo ya era agente de salud, ¿verdad? De ahí yo entregaba, yo comenzaba a atender a las personas de fuera. De ahí el viernes, después de que cerraba mi horario en el puesto, comenzaba a las cinco de la tarde, hasta el domingo yo atendía, principalmente a los de fuera. Yo entrego más de 60, 70 litros sólo el fin de semana. De ahí empecé y de ahí ellos me preguntan si tengo curso de hierbas medicinales. Yo dije: "tengo curso de hierbas medicinales por la Pastoral de la Salud, sólo ese don que Dios que me

Blanco es un término utilizado por los kaingang para referirse a la población local no indígena que con frecuencia desciende de inmigrantes europeos, sobre todo italianos y alemanes. 


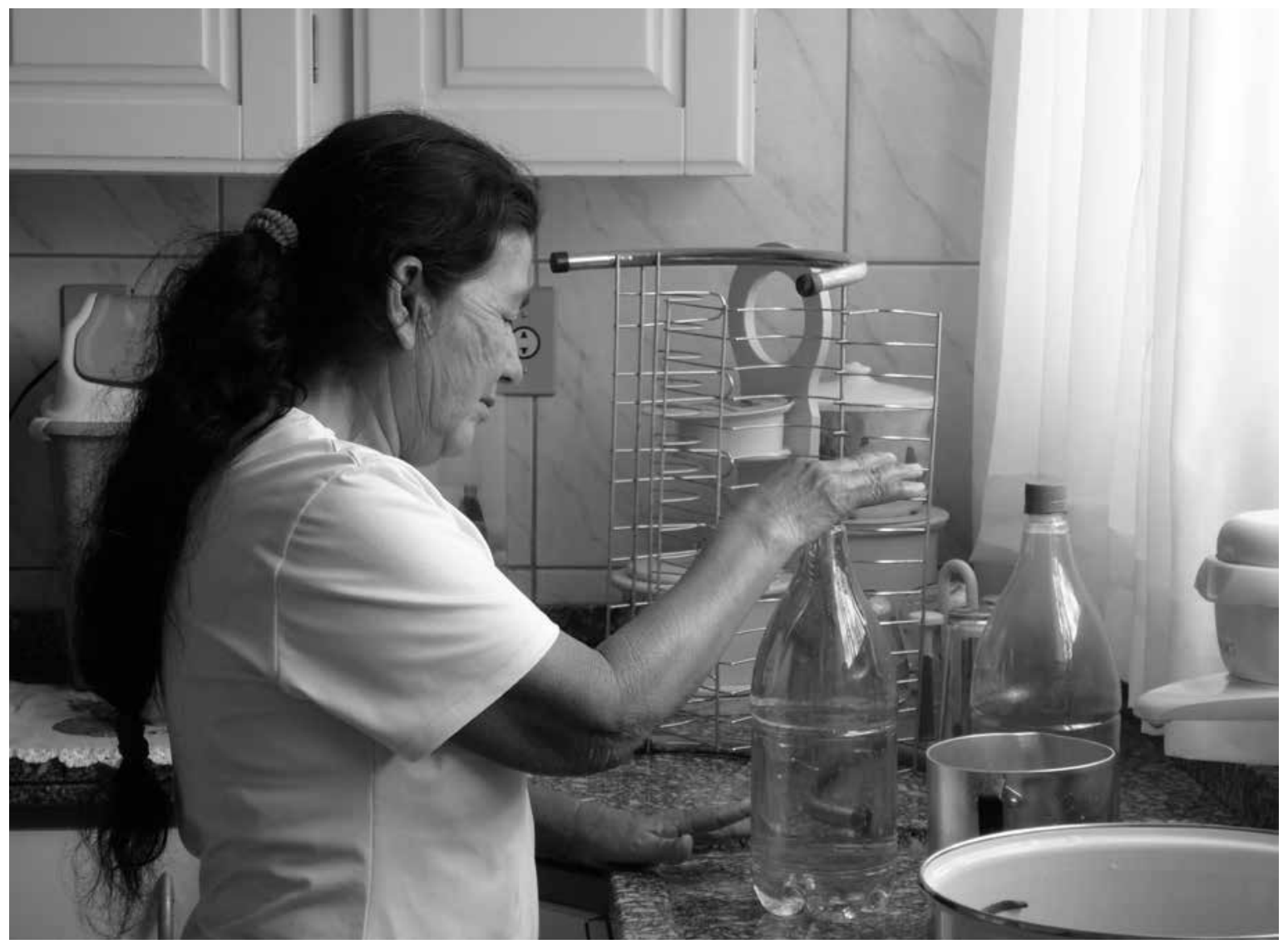

ARI GHIGGI JUNIOR • Preparación de botellas con infusión de hierbas.

dio”, ¿no? Fue allí donde yo empecé, ahí aprendí a orar. De ahí fui a la iglesia y de ahí Dios me dio más dones, ¿verdad? Dios me bendijo más. Me dio más fuerza (entrevista con Luciana, Terra Indígena Xapecó, 18 de diciembre de 2013).

El "don de las hierbas medicinales" no es un don espiritual habitual entre los creyentes. Al saber que los conocimientos sobre los "remedios del monte" se asocian en la localidad a elementos de afirmación y construcción de la identidad indígena, Luciana demuestra habilidad en la articulación de la llamada “tradición” en su práctica creyente.

Según Veiga (2004), los kaingang se refieren a esa tradición cuando afirman que su primera religión fue católica. Para esta autora, "el catolicismo popular 'bebió' de la cosmología indígena y fue fuertemente influenciado por ella, de la misma forma en que los indígenas absorbieron elementos del catolicismo en sus prácticas rituales" (2004: 176). Oliveira afirma que "algunos de los indios más viejos de Xapecó, empeñados en preservar la cultura, cuando hablan de la tradición y la costumbre son unánimes al afirmar que el 'Ritual del

El remedio del monte es una categoría utilizada para designar a las plantas que poseen alguna característica terapéutica. Se asociada al papel de prácticas de la tradición indígena. 
$\mathrm{Kiki}^{10}$ es la religión de los kaingang' y que participar en el Kiki y ser ‘católico’ es lo mismo” (1996: 13). Así, en la TIX es común que se incluyan elementos de esta tradición, como algunos santos del panteón católico local que no aparecen en la lista oficial de la iglesia; por ejemplo, Nuestra Señora Aparecida, san Sebastián o san Juan María. ${ }^{11}$ La tradición se caracteriza también por algunas actividades específicas, como rezos del rosario en las casas y fiestas de santos, procesiones y bautizos. La (re)producción de estos saberes y prácticas está ligada a las actividades terapéuticas de los rezadores del rosario, las benzedeiras, las curanderas, los fiesteros de santos o incluso los kuiã. ${ }^{12}$

En este contexto, la preparación de las aguas de hierbas no se reduce a la infusión de hierbas en agua caliente. La parte fundamental del proceso de producción es la bendición de la sustancia, otro aspecto que evidencia una redefinición de los elementos simbólicos en cuanto a la entidad espiritual que se pretende convocar. En las prácticas localmente asociadas a la tradición, por lo general se pide que algún santo católico, casi siempre el patrono de la persona que prepara el agua, coloque su fuerza y sabiduría de curación en la sustancia. Como los creyentes no conciben en sus formulaciones a los santos y sus representaciones en imágenes, ahora Luciana hace oración ${ }^{13}$ sobre el agua de hierbas y le pide a Jesús que la bendiga. Explica que entre los evangélicos el uso de esas aguas está prohibido cuando contienen alguna sustancia alcohólica.

Esta articulación también está presente en la argumentación de Luciana sobre los procesos de transferencia de los saberes de las hierbas medicinales a otras personas, en los que el don, además de prerrequisito, es una predisposición involuntaria designada por Dios: "no sirve enseñar, necesita tener don para aprender". Luciana percibe, sin embargo, que para el desarrollo de este don también son fundamentales algunas prácticas iniciáticas consideradas tradicionales, como lavar al niño con los remedios del monte:
Enseñé allí en el Imbu [Abelardo Luz] a unas tres personas, pero tiene que tener el don, porque la persona que no tiene el don, no lo domina, no se interesa, no lo graba en la cabeza. Creo que Camila va a heredar mi don, ella y ese niño. Este niño va a heredar mi don, porque cuando voy a hacer remedio él está viendo, cuando yo recojo remedio él va junto, pregunta y ya sabe. Y la tía María lo lavó con

10 El Ritual del Kiki es una ceremonia de culto a los muertos en la que los vivos se encuentran con los antepasados. Se utiliza una araucaria, como un cocho, para la preparación del Kiki, la bebida ritual. Si se prepara de manera tradicional, es un fermentado a base de agua, miel y sámora. En fechas más recientes, se hace con aguardiente $u$ otras bebidas alcohólicas. Los participantes se adornan con pinturas corporales, según la pertenencia a las mitades exogámicas, que expresan la concepción del mundo y la organización social a partir de las funciones ceremoniales (Crépeau, 1994). El último Kiki del que se tiene registro en la tix data de 1998 (Tommasino y Rezende, 2000). Según interlocutores indígenas, su continuidad se vio afectada por el fallecimiento de los rezadores. En la actualidad, Luciana está involucrada en la discusión de la revitalización del ritual con líderes indígenas de la TIX y otros actores importantes, como parientes de antiguos rezadores. Llama la atención la presencia de creyentes en la comisión organizadora y algunas adaptaciones al contexto actual de la TIX, como la utilización de dos tipos de sustancias rituales, una fermentada y otra no.

11 Se dice que san Juan María es un astuto peregrino que aún camina por la Tierra. Cuando encuentra a alguien en sus andanzas por la TIX, puede demostrar poderes curativos o hacer profecías acerca de la decadencia de los modos de vida tradicionales y la llegada de un apocalipsis. Es una figura asociada por la literatura a uno de los monjes que participaron en la Guerra del Contestado, un conflicto que redefinió los límites entre los estados de Paraná y Santa Catarina, en 1917.

12 Kuiã es el chamán kaingang. Tiene el poder de entrar en contacto con los espíritus-guías animales, iangré, por medio del sueño para obtener informaciones acerca de diagnósticos y procedimientos para el tratamiento de desgracias en general (Veiga, 2006).

13 La oración es una práctica individual cotidiana entre los creyentes y no es necesario estar en lugares adecuados para efectuarla. Se trata de agradecimientos o pedidos individuales hechos en voz alta a Dios para satisfacer diversas necesidades. 
remedio allá en el bosque, allá arriba, y ahí da ese don (entrevista con Luciana, Terra Indígena Xapecó, 18 de diciembre de 2013).

A pesar de que subraya y reinterpreta su práctica terapéutica a partir de su condición actual de practicante evangélica, Luciana pasó por otros ambientes en su proceso de aprendizaje. Tal vez uno de los más importantes fue el familiar. Su familia era una de las organizadoras del Ritual del Kiki, principalmente su padre, hasta la última vez que se realizó, en 1998, lo que sin duda influyó en su postura actual acerca del mantenimiento de esta tradición indígena. Cuenta que aprendió mucho sobre los remedios del monte con su padre, ya fallecido, y su tía, una vieja indígena reconocida en la TIX por sus prácticas terapéuticas en esta especialidad.

Sumado a ello, Luciana considera importantes para su aprendizaje los cursos sobre hierbas medicinales ofrecidos por la Pastoral de la Salud..$^{14}$ En su práctica, aproxima las categorías de remedios del monte y hierbas medicinales y las trata como sinónimos, aunque reconoce que los remedios del monte, en el sentido tradicional, son más poderosos que las hierbas medicinales porque crecen de manera espontánea como malezas.

Recuerda con nostalgia su actividad como partera. Hoy no lo hace más, pues el procedimiento estándar de las embarazadas en la TIX es el ingreso al hospital, con un alto índice de cesáreas. Hace muchos años trabajó en la antigua enfermería de la aldea sede ${ }^{15}$ como auxiliar. Considera que esta experiencia fue relevante para su ejercicio de partera, a pesar de que utiliza poco los conocimientos biomédicos para justificar su práctica actual y de que en diversas ocasiones la vi recetar paracetamol, además de su agua de hierbas.

Cuando Luciana habla de las posibilidades de tratamiento ofrecidas a partir de su don, cita enfermedades diagnosticadas en la TIX, como el "amarillón”, y otras reconocidas por la biomedicina, como el cáncer, el síndrome de inmunodeficiencia adquirida (sida) o los problemas de próstata. Sus evaluaciones sobre la lógica del tratamiento y diagnóstico de las enfermedades por lo general destacan las dificultades de los médicos para reconocer los límites de su propio conocimiento:

La mayoría de las mujeres tiene infección en el ovario, en las trompas, quistes, también amarillón y anemia. A veces confunden amarillón con anemia. Yo digo: "no, amarillón es una cosa y la anemia es otra". Porque digo que cada caso es un caso, el amarillón ataca el hígado y la anemia no, la anemia es en la sangre, ¿no? A veces el blanco va a hacer exámenes, ahí el médico dice que está con anemia. El amarillón amarilla las vistas, da mucho sueño, dolor en el cuerpo y falta de apetito. Entonces la anemia es más peligrosa que el amarillón, porque si no la trata da leucemia. Y si no cura el amarillón, mata también, se convierte en hepatitis. Porque los médicos no dicen amarillón, ellos dicen hepatitis, ¿no? Porque nosotros, que somos así, las personas del interior, entendemos como amarillón lo que para los médicos es hepatitis. Nosotros hacemos tratamiento con siete hierbas y tienen que ser amargas. Hay muchos que hacen agua de hierbas dulces, pero no se puede, porque él ataca el hígado.

14 La Pastoral de la Salud es un organismo de acción social relacionado con los sectores asistencialistas de la Iglesia católica. Empezó sus actividades en la TIX alrededor de 1993, con un plantío de huertas comunitarias, e incentivó el uso de hierbas medicinales. La Pastoral produce y distribuye tintes, jabones, pomadas y jarabes para enfermedades leves, para la población local.

15 En 1981 se instalaron las primeras enfermerías en la tIX. Hoy son cinco puestos de salud de atención primaria con el equipo multidisciplinario de salud indígena, que cuenta con un médico, enfermeras, un nutricionista, un auxiliar de dentista, técnicos en enfermería y agentes indígenas de salud. Los papeles desempeñados por el equipo obedecen a una jerarquía que implica la distribución de actividades y poder de decisión, lo cual, en la tIX, atraviesa contextos sociopolíticos locales (Diehl, 2001). 
Entonces tiene que ser amargo, porque mata el animalito del hígado. Cáncer también, ¿no? Cuando ellos examinan, entonces ellos cuentan dónde está el tal cáncer. Entonces ya hago el medicamento y ya vienen a buscarme por el medicamento. Yo doy hierba malvón para el cáncer. Los hombres de allá afuera también me buscan mucho con problemas de próstata y también les receto su agua de hierbas (entrevista con Luciana, Terra Indígena Xapecó, 18 de diciembre de 2013).

En última instancia, para Luciana, el saber biomédico es limitado por definición, porque "sólo Dios puede curar cualquier enfermedad". Incluso cuando un médico cura una enfermedad compleja, es Dios quien está orientando o permitiendo la curación. Ante esta omnipotencia, desde su conversión, Luciana reinterpreta los acontecimientos de su trayectoria de vida, la diversidad de aprendizajes terapéuticos con los que ha tenido contacto y entiende su propia práctica dentro de la lógica evangélica, como resultado de un "plan divino" que se manifiesta por medio de su cuerpo.

\section{Dinámicas de circulación}

Fueron pocos los momentos en los que acompañé a Luciana a tratar personas en su propia aldea. De hecho, durante la investigación ella estaba muy orientada a atender sujetos fuera del área indígena, los visitaba en Xanxerê y Abelardo Luz. La acompañé con frecuencia en sus viajes a Xanxerê, con una logística que era casi idéntica todas las veces.

Muy temprano, a eso de las seis de la mañana, despertábamos y nos preparábamos para tomar el autobús hacia la ciudad. Días antes, Luciana se ponía de acuerdo con su amiga Arlete, la mujer que nos recibiría en la ciudad. Mientras yo tomaba café junto al pequeño Juliano, nieto de Luciana, ella salía de casa con discreción e iba al puesto de salud, todavía cerrado a esa hora. La veía cuando ella entraba en el patio, donde había una antigua huerta de hierbas medicinales, construida hace tiempo por los funcionarios del puesto. Permanecía allí unos minutos y regresaba con un paquete de hierbas, hojas y ramas de plantas que colocaba en una bolsa de plástico. En una ocasión le pregunté si ésos eran los remedios que utilizaba para atender al personal de la ciudad: "sí, son remedios del monte", respondió rápidamente.

Luciana tomaba un poco de café, alistaba a su nieto y esperábamos el autobús delante de la casa. El autobús pasaba, como todos los días, a las 7:30. Abordábamos y unos 45 minutos después llegábamos a Xanxerê. Bajábamos en un lugar periférico, un poco distante del centro de la ciudad. Entrábamos por una calle alejada y recorríamos unos $500 \mathrm{~m}$ de un barrio de casas. En el camino, Luciana avistaba y recogía la rama de algún árbol plantado en la calle y la juntaba con las otras hojas en la bolsa: “ése, aquí, también es remedio, para infección”, decía. Caminábamos un poco más hasta llegar al barrio donde vivía su anfitriona. Se diferenciaba del anterior por las casas más simples y las calles sin pavimento. Parecía ser un lote nuevo. Arlete nos recibía con el desayuno.

Arlete es hermana de Ignacio, un indígena que yo conocía, que trabajaba como técnico de enfermería en el puesto de salud de la aldea Fazenda São José en la TIX: "somos hermanos por parte de madre, ella era indígena; mi padre era un italiano, aquí, de Xanxerê. Yo viví un tiempo en el área. Después, cuando crecí, venimos aquí y me casé" (entrevista con Arlete, Xanxerê, 20 de diciembre de 2013). Arlete traía pedidos de Paraguay, compraba y revendía mercancías para algunos clientes específicos en la ciudad. Me contó que Luciana la había curado de un problema de salud y a partir de entonces comenzó una amistad intensa.

Cierto día, después del café, subimos al carro de Arlete, quien nos llevó a otra casa ubicada en un 
barrio más central de Xanxerê y de mayor estrato socioeconómico que el suyo. La casa grande era de Isabel y su familia. Hablamos con ella y advirtió que pronto llegarían sus cuatro amigas, quienes arribaron unos 15 minutos después. Saludaron e Isabel les presentó a Luciana: "ésta es nuestra médica". En unos momentos, la casa de Isabel se convirtió en el consultorio de Luciana. Nos ubicamos en un área externa, separada de la cocina por una puerta. Luciana preguntó a cada una sobre sus problemas. Una respondió que tenía un problema en la rodilla, otra que sufría de depresión y a las otras dos no les entendí.

Mientras esperábamos, Luciana fue a la cocina a preparar el agua de hierbas. Tomó dos ollas, las llenó de agua y las puso a hervir. Separó ramas de las hojas que traía consigo y las puso en las ollas. Esperó el hervor y apagó el fuego. Colocó la tapa sobre las ollas y las dejó ahí.

Las mujeres esperaban afuera y conversaban sobre las experiencias y síntomas de las enfermedades que padecían. En esa conversación descubrí que sólo una era amiga de Isabel, quien llevó a las otras dos para esa ocasión. Fue interesante que esta conversación transformara la casa de Isabel en una sala de espera en la que se compartieron las experiencias de las enfermedades. Isabel recomendaba la actividad de Luciana. Comentó que tenía un problema en la rodilla y se había operado, que siempre le dolía, pero mejoraba con la infusión de Luciana. Isabel comentó en varias ocasiones que "los indios saben bastante de medicinas y hierbas" y coincidió con otra de las señoras en que había "mucha pobreza en el área indígena” (notas de campo).

Luciana terminó de preparar las aguas y llenó cuatro botellas de dos litros cada una. No me di cuenta de que hubiera hecho aguas diferentes para cada mujer, a pesar de que en las conversaciones afirmó que cada hierba servía para un tipo de enfermedad. Luciana llamó a cada mujer por separado. La que entraba en la cocina se sentaba en una silla al lado de la mesa donde estaba la botella de la infusión. Luciana preguntaba el nombre de la mujer, ponía la mano derecha sobre la botella y hacía una oración. Después se volvía hacia la mujer sentada, ponía la mano sobre su cabeza y hacía otra oración en voz alta: "Padre, saca esa enfermedad del cuerpo de esa persona, eres un gran padre, lo ponemos todo en tu mano. Este remedio, Padre, bendice este remedio, para quitar la enfermedad, para toda tu gloria, salva a tu hija que cree en tu poder, $\mathrm{Pa}-$ dre, amén”. Luciana miraba a la persona y pasaba a la prescripción: "puede tomar el agua tres veces al día, un vaso cada vez, usted va a ver, mañana ya va a estar mejor, ¿sí??". Al terminar, cada mujer le entregaba diez reales. Luciana dijo que estaría de vuelta en diez días y que las mujeres debían volver para reforzar el tratamiento.

Todas le agradecieron y se marcharon. Isabel dijo que en diez días las recibiría de nuevo en su casa. Arlete y Luciana agradecieron y subimos al coche de Arlete, que nos dejó en el centro de la ciudad de Xanxerê para ir a casa de Marta, otra clienta de Luciana.

Marta y su hermana Meire conocieron a Luciana unos días antes, también en casa de Isabel, por intermedio de Arlete. En esa ocasión, Luciana le informó que necesitaría más atención para que el tratamiento fuera eficaz debido a la gravedad del problema. El caso de Marta parecía complicado, pues la primera vez que se encontró con Luciana habló poco, mantuvo un semblante de tristeza y lloró varias veces. Como era poco comunicativa, la acompañaba Meire, su hermana menor. En la primera sesión, Luciana había hecho oraciones para las dos hermanas y un té para Marta. Vi que Meire dejó 50 reales como contribución. En la segunda visita, fuimos a la casa de Marta, que en realidad vivía con la familia de Meire. Era un apartamento amplio en un edificio de tres pisos en el centro de Xanxerê, propiedad de su familia. Por la conversación que tuve después con Meire, supe que poseían otros inmuebles, fruto de la carrera de Meire y su marido, 


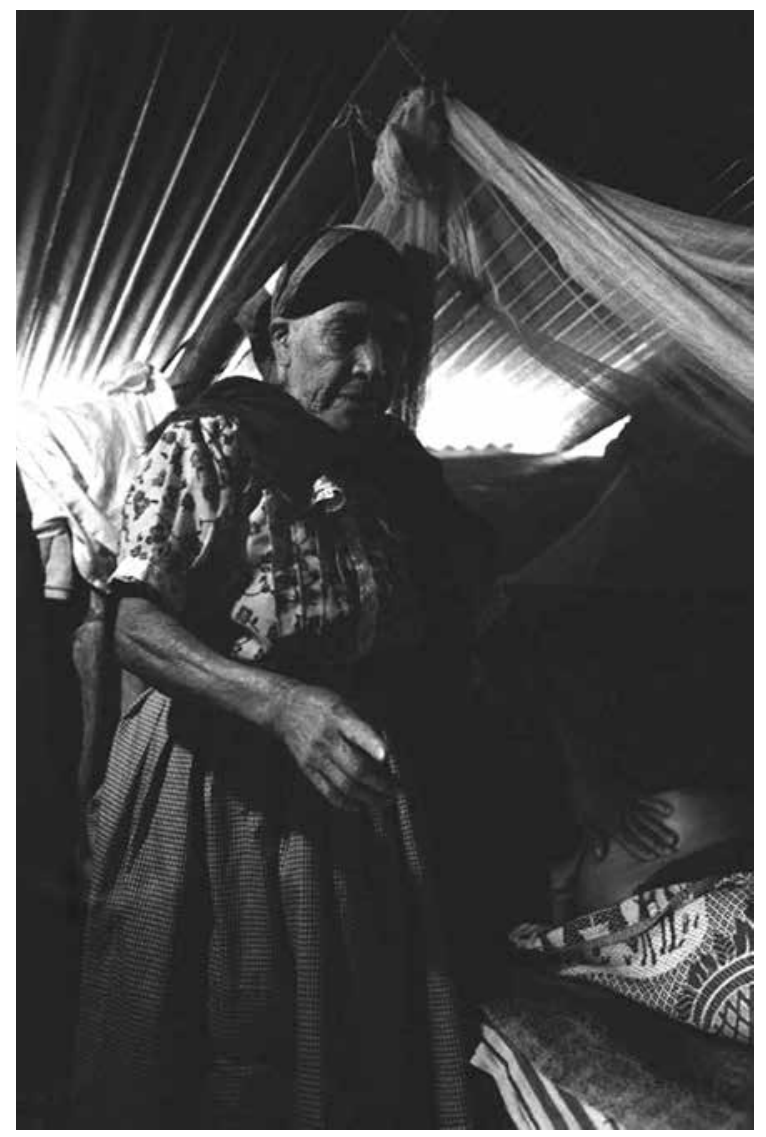

RicARDo Ramirez ARRIola - Las comadronas alternan la atención a las embarazadas con la práctica de la herbolaria, el cuidado de la milpa y la siembra. San Pedro Pinula, Jalapa, Guatemala, 2000.

Arsenio, en el comercio local. Marta era muy conocida por su carrera de educadora en uno de los principales colegios públicos de la ciudad. Luciana, su nieto y yo fuimos recibidos por Meire. Camino hacia la cocina, encontramos a Marta sentada leyendo la Biblia. Luciana la saludó y le preguntó cómo estaba. Ella no hablaba mucho, sólo lloraba. La dejamos sola y nos dirigimos al fondo, a la cocina. Meire me dijo que su hermana sólo lloraba, pero que había mejorado desde la última vez que Luciana la había atendido. Luciana hizo el mismo procedimiento, fue a la cocina, separó las hierbas y las cocinó en una olla. Después llenó dos botellas desechables de dos litros e hizo oración sobre ellas. Luciana quiso conocer la habitación de Marta. Encima de su cama, extendió la mano e hizo una oración.

Meire nos acompañó hasta la puerta, Luciana dijo que sería bueno volver otras veces. Meire dijo que hablaría con Arlete para saber la mejor fecha y entregó una contribución en efectivo a Luciana. También le donó dos grandes bolsas de ropa usada. Arsenio nos llevó a la carretera para tomar el autobús.

Estas consultas ocurrieron por la mañana. Por la tarde, dejamos las mochilas y bolsas en el guardarropa de la terminal de autobuses, almorzamos y fuimos al supermercado a comprar víveres. A las cuatro de la tarde regresamos a la casa de Luciana en la aldea sede de la TIX. Por la noche, Luciana tenía el compromiso de asistir al culto de su iglesia. Cabe mencionar que los desplazamientos de Luciana se parecen mucho a los de su tía María, quien también va a las ciudades vecinas a distribuir infusiones de remedios del monte, con la diferencia de que ella no es creyente.

Luciana también interviene en otro tipo de articulación mediada por su conocimiento e inserción en prácticas de salud. Desde hace años, muchos investigadores la visitan en la TIX. Yo mismo me alojé varias veces en su casa. Esta relación se cultivó después de la muerte de su padre, Antonio, un indígena muy involucrado en las actividades políticas en torno a la valoración de la cultura y la tradición kaingang. Las relaciones de Luciana con los investigadores, de programas de historia, farmacia, nutrición y antropología principalmente, resultan en viajes a Florianópolis, capital del estado, y visitas a sus casas, aunque su motivación principal es visitar a su hijo, quien vive y trabaja en una ciudad vecina. Su conocimiento de prácticas de atención vinculadas a las plantas, hierbas o remedios del monte, incluso sobre el parto, también han derivado en su participación en congresos de fitoterapia para los alumnos del curso de licenciatura intercultural indígena de la Universidad Federal de Santa Catarina (UFSC) y otros eventos de esta institución. 
Este conocimiento del mundo exterior, del blanco, y las relaciones con sujetos "de fuera", en las que Luciana se muestra habilidosa, también la convierten en referente para auxiliar a personas enfermas en otros contextos de la TIX que se extienden por la región más cercana. Estuve con Luciana en el caso de Andreia, una joven indígena que padecía cáncer en la cara, diagnosticado por los médicos del sistema público en Xanxerê. Después de intentar todas las posibilidades de tratamiento disponibles en la región, incluso sesiones de quimioterapia en el hospital regional de Xapecó, el avance de la enfermedad hizo que Andreia fuera enviada al Centro de Investigaciones Oncológicas (Cepon, por su acrónimo en portugués), en Florianópolis. Como Andreia no conocía la ciudad y necesitaba un acompañante, su madre buscó a Luciana para que hicieran el viaje juntas. Un vehículo de la Secretaría de Salud de la Alcaldía de Ipuaçu ${ }^{16}$ las llevó a la capital y se hospedaron en una casa de apoyo ${ }^{17}$ durante los días de tratamiento. Cada viaje duraba alrededor de una semana para cumplir un ciclo de quimioterapia. Como el vehículo no quedaba a su disposición en Florianópolis, Luciana utilizaba el sistema de autobuses de la ciudad. En ocasiones críticas, recurrió a los investigadores para que la auxiliaran a trasladar a Andreia de la casa al Cepon y viceversa. Los investigadores también les daban ayuda monetaria para hacer el viaje un poco menos costoso. Andreia y Luciana repitieron este trayecto a Florianópolis pocas veces, pues entre fases buenas y malas, la joven falleció meses después del primer viaje.

\section{Consideraciones finales}

En este texto intenté explorar los procedimientos para la oferta de prácticas terapéuticas de Luciana con el fin de ilustrar el pluralismo médico local como una zona intermédica emergente, en la que se enfatiza la autonomía indígena frente a los procesos de hegemonía y subalternidad que recorren el campo de la atención a la salud. En la composición de su práctica se articulan los diversos saberes que Luciana adquirió en su trayectoria de vida. Hay elementos considerados tradicionales en el ámbito local, relacionados con los remedios del monte, heredados del seno familiar y complementados con cursos sobre fitoterapia de la Pastoral de la Salud, así como saberes biomédicos, provenientes de su experiencia como auxiliar de enfermería en el puesto de salud local, además de las concepciones y prácticas evangélicas de su conversión a las iglesias pentecostales que ejercen en la TIX.

Desde una perspectiva crítica, la preocupación de Luciana se orienta más a establecer diálogos entre las tradiciones médicas, que a negar algunas de ellas. Lo que ocurre es una valoración de las concepciones cristianas evangélicas que ayudan a justificar su práctica actual y reinterpretar su trayectoria desde la perspectiva creyente. El fundamento religioso le permite buscar las causas de las enfermedades y proponer soluciones amplias, en las que la resignificación e incorporación de elementos de los saberes terapéuticos pasan a formar parte del conjunto de argumentos para la difusión de la palabra de Dios.

Por lo tanto, la cuestión de la resistencia contrahegemónica, analizada desde el punto de vista

Todas las alcaldías de las pequeñas ciudades del interior del estado invierten parte de su presupuesto en la compra de automóviles y ambulancias para trasladar a sus habitantes hacia centros principales de atención a la salud.

17 Las casas de apoyo son alojamientos colectivos vinculados a organizaciones no gubernamentales $u$ organizaciones de la sociedad civil de interés público para acoger a familiares de pacientes en tratamientos en los hospitales en varias ciudades del estado. Se enfocan en la circulación de personas oriundas de las más diversas localidades que no poseen recursos para pernoctar en otro lugar. Las casas ofrecen camas y alimentos básicos, recaudados mediante donación para preparación colectiva por parte de los beneficiados, quienes también se encargan de la limpieza y el mantenimiento del espacio. 
pragmático a partir de los procedimientos de Luciana, también revela estrategias para establecer vínculos con los no indígenas y desarrollar relaciones de clientela en las que se afirma como referencia terapéutica. Además, esas estrategias demuestran un conocimiento excepcional de las localidades del entorno de la TIX, construido sobre la base de su circulación por los centros urbanos regionales en función de su trabajo.

Por un lado, su conocimiento de las localidades la convierte en referente importante para auxiliar a los que necesitan circular por estos espacios, lo que se corrobora por la centralidad de las mujeres en la gestión de los procesos de salud/enfermedad/ atención en la TIX. Por otro lado, esta circulación permite el establecimiento de redes de actividad terapéutica que conllevan aspectos de cooperación y aproximación para el acceso a círculos más específicos, como los estratos sociales de familias no indígenas acomodadas.

Luciana aprovecha su práctica para fortalecer su empoderamiento en el desempeño de un papel más simétrico en el campo de las relaciones interétnicas locales. Así, la cuestión de la hegemonía y la subalternidad tiene efectos sobre las posibilidades de autonomía de los kaingang, una vez que la articulación de los saberes pasa y pone en primer plano la cuestión de la precarización de las formas de subsistencia en el contexto de desigualdad y pobreza. Por lo tanto, la emergencia de las relaciones fomentadas por Luciana en la atención a los no indígenas también se relaciona con la obtención de alimentos, ropa, dinero y otros recursos de subsistencia. Así, si consideramos que sus procedimientos tienen por finalidad última subsidiar las posibilidades de reproducción biosocial del grupo doméstico de forma autónoma, podemos entender sus actividades como una práctica de autoatención en sentido amplio, conforme a lo propuesto por Menéndez (2009).

Tratar la intermedicalidad y los procedimientos de oferta terapéutica en la emergencia de una práctica híbrida y dinámica, en un contexto indígena, es un intento de problematizar la imagen romantizada e hiperreal del indígena, apoyada en una noción esencialista de la cultura, que subyace en las miradas externas y los estereotipos sobre estas poblaciones. Para Bartolomé (2005), hablar de hibridismo al tratar los aspectos culturales presentes en poblaciones indígenas es, en realidad, una tautología, pues, por definición, las culturas en general siempre han sido híbridas y dinámicas. Culturas e identidades son resultado de sistemas interactivos que constituyen expresiones contextualizadas en procesos de estructuración y reestructuración histórica. Al acuñar la noción de situación etnográfica para definir a los indígenas como sujetos históricos plenos, Oliveira Filho (1999) trata como un grave equívoco la exacerbación de la singularidad de las culturas indígenas al considerarlas incontaminadas por las instituciones coloniales. Así, para ser componentes legítimos de una cultura, los rasgos no necesitan ser exclusivos de esa sociedad, pueden compartirse con otras poblaciones. Tampoco necesitan ser ancestrales o antiguos, pueden constituirse en la adaptación de pautas culturales en el mundo moderno y globalizado. Transfiguración étnica es el nombre que Bartolomé da a este proceso de adaptabilidad estratégica que las sociedades subordinadas generan para sobrevivir en el tiempo, que desenfocan en el proceso su propio perfil cultural. Los mecanismos presentes en las transfiguraciones étnicas comprenden la autonomía de sujetos sociales que interactúan con las estructuras coyunturales. Se trata de aceptar que las culturas poseen configuraciones dinámicas creadoras del presente y que tal vez nunca haya existido una configuración esencial, sino configuraciones sucesivas entre las cuales está la que se manifiesta en el presente.

Por lo tanto, las formas en que se presentan las religiosidades cristianas en la TIX remiten a una continuidad, a un telón de fondo común que va más allá de los aspectos simbólicos que las separan. 
Las representaciones y prácticas asociadas a las religiosidades locales nos hacen pensar en la existencia de una cosmología de fondo, presente y compartida por los indígenas; una lógica sobre la cual emerge como respuesta una cierta visión del mundo. Es decir, las actuaciones pragmáticas, las dinámicas de circulación, y sobre todo, la agencia kaingang, remiten a una transfiguración étnica que denota la manera en la cual la configuración cultural se expresa en la actualidad por la vía de la religiosidad. En este sentido, las praxis relacionadas con el cristianismo podrían tomarse como extensión de las propias cosmologías nativas, como demostraron diversos autores en relación con otros grupos indígenas brasileños (Wiik, 2004a; 2004b; Wright, 1999; Veiga, 2004; Vilaça y Wright, 2009).

Esta discusión ilumina la comprensión sobre la medicina tradicional como categoría que evita la especialización y la demarcación de fronteras culturales rígidas para, ante todo, ser tomada como emergente en los contextos interculturales (Menéndez,
1994). Así, la cuestión del pluralismo médico como contexto intermédico se refiere a las influencias, en términos de las referencias terapéuticas y los modelos de atención dinámicos, que resultan en especialistas que utilizan las terapias disponibles. En otras palabras, estas reformulaciones no significan la desestabilización de las identidades étnicas.

El argumento acerca de los cambios y la pérdida de los rasgos culturales originales parte de una posición hegemónica y sirve a la reproducción de las relaciones asimétricas en el campo interétnico, que por desgracia orienta acciones institucionalizadas que median el acceso de los indígenas a las políticas públicas sobre salud y derechos en general. Entender el pluralismo médico desde la perspectiva de la intermedicalidad y la emergencia de las prácticas terapéuticas de Luciana es una tentativa de valorar sus posibilidades de autonomía, superar imposibilidades epistemológicas y respetar a las sociedades y las configuraciones culturales que asumen los indígenas, sin juzgarlos. D

\section{Bibliografía}

Almeida, Ledson Kurtz de, 1998, Dinâmica religiosa entre os kaingang do posto indígena Xapecó-sc, tesis de maestría en antropología social, Universidade Federal de Santa Catarina, Florianópolis.

Baer, Hans, Merril Singer y John Johnsen, 1986, “Toward a Critical Medical Anthropology”, en Social Sciences \& Medicine, vol. 23, núm. 2, pp. 95-98.

Bartolomé, Miguel A., 2005, Procesos interculturales: antropología política del pluralismo cultural en América Latina, Siglo XXI Editores, México.

Crépeau, Robert, 1994, “Mythe et rituel chez les indiens kaingang du Brésil méridional”, en Religiologiques, núm. 10, pp. 143-157.

Diehl, Eliana Elisabeth, 2001, Entendimentos, práticas e contextos sociopolíticos do uso de medicamentos entre os kaingáng (Terra Indigena Xapecó, Santa Catarina, Brasil), tesis de doctorado, Fundação Oswaldo Cruz, Río de Janeiro.

Follér, Maj-Lis, 2004, “Intermedicalidade: a zona de contato criada por povos indígenas e profissionais de saúde”, en Esther Jean Langdon y Luiza Garnelo (orgs.), Saúde dos povos indígenas: reflexões sobre antropologia participativa, Associação Brasileira de Antropologia/ ContraCapa, Río de Janeiro, pp. 129-148.

Frankenberg, Ronald, 1980, "Medical Anthropology and Development: A Theoretical Perspective”, en Social Science \& Medicine, Medical Anthropology, vol. 14b, núm. 4, 197-207.

Ghiggi Junior, Ari, 2006, Representações e práticas no tratamento de infortúnios entre os kaingang crentes da aldeia sede da Terra Indigena Xapecó, tesis de licenciatura en ciencias sociales, Universidade Federal de Santa Catarina, Florianópolis.

—_, 2010, Estudo etnográfico sobre alcoolização entre os indios kaingang da Terra Indígena Xapecó: das dimensões construtivas à perturbação, tesis de maestría en antropología social, Universidade Federal de Santa Catarina, Florianópolis. 
—_ 2015, Uma abordagem relacional da atenção à saúde a partir da Terra Indígena Xapecó, tesis de doctorado en antropología social, Universidade Federal de Santa Catarina, Florianópolis.

Ghiggi Junior, Ari y Esther Jean Langdon, 2013, "Controle social como autoatenção: estratégias kaingang diante os abusos das bebidas alcoólicas", en Maximiliano Loiola Ponte de Souza (ed.), Processos de alcoolização indígena no Brasil: perspectivas plurais, Fundação Oswaldo Cruz, Río de Janeiro, pp. 159-178.

__ 2014, "Reflections on Intervention Strategies with Respect to the Process of Alcoholization and Self-Care Practices among Kaingang Indigenous People in Santa Catarina State, Brazil”, en Cadernos de Saúde Pública, vol. 30, núm. 6, pp. 1250-1258.

Greene, Shane, 1998, "The Shaman's Needle: Development, Shamanic Agency, and Intermedicality in Aguaruna Lands, Peru”, en American Ethnologist, vol. 25, núm. 4, pp. 634-658.

Instituto Brasileiro de Geografia e Estatística (IBGE), 2012, Os indígenas no censo demográfico: primeiras considerações com base no quesito cor ou raça, Instituto Brasileiro de Geografia e Estatística, Río de Janeiro, Disponible en línea: <http://www.ibge.gov.br/indigenas/indigena_censo2010.pdf>.

Instituto Socioambiental (ISA), 2015, "Terra Indígena Xapecó: povos e demografia", en Terras Indígenas no Brasil. Disponible en línea: <http:// ti.socioambiental.org/pt-br/\#!/pt-br/terras-indigenas/3906>.

Langdon, Esther Jean y Marina Cardoso (eds.), 2015, Saúde indígena: políticas comparadas na América Latina, Universidade Federal de Santa Catarina, Florianópolis.

Menéndez, Eduardo, 1994, “La enfermedad y la curación. ¿Qué es medicina tradicional?”, en Alteridades, vol. 4, núm. 7, pp. 71-83. , 2009, Sujeitos, saberes e estruturas: uma introdução ao enfoque relacional no estudo da saúde coletiva, Hucitec, São Paulo.

Oliveira, Maria Conceição de, 1996, Os curadores kaingang e a recriação de suas práticas: estudo de caso na aldeia Chapecó (oeste S. C.), tesis de maestría en antropología social, Universidade Federal de Santa Catarina, Florianópolis.

Oliveira Filho, João Pacheco de, 1999, Ensaios em antropologia histórica, Editora de la Universidade Federal do Rio de Janeiro, Río de Janeiro. Ortner, Sherry, 2007, "Poder e projetos: reflexões sobre a agência”, en Miriam Grossi, Cornelia Eckert y Peter Fry (eds.), Conferências e diálogos: saberes e práticas antropológicas, Associação Brasileira de Antropologia/Nova Letra, Brasilia y Blumenau, pp. 45-80.

Scopel, Daniel, Raquel Paiva Dias-Scopel y Flávio Braune Wiik, 2012, "Cosmologia e intermedicalidade: o campo religioso e a autoatenção às enfermidades entre os índios munduruku do Amazonas, Brasil”, en Tempus: Actas de Saúde Coletiva, vol. 6, núm. 1, pp. 173-190.

Seppilli, Tullio y Rosario Otegui, 2005, "Antropología médica crítica: presentación”, en Revista de Antropología Social, vol. 14, pp. 7-13. Singer, Merrill, 1990, "Reinventing Medical Anthropology: Toward a Critical Realignment", en Social Science \& Medicine, vol. 30, núm. 2, $179-187$.

Tommasino, Kimiye y Jorgisnei Ferreira de Rezende, 2000, Kikikoi: ritual dos kaingang na área Indígena Xapecó/sc. Registro ÁudioFotográfico do Ritual dos Mortos, Midiograf, Londrina.

Veiga, Juracilda, 2004, "As religiões cristãs entre os kaingang: mudança e permanência”, en Robin Wright (ed.), Transformando os deuses, vol. 2: Igrejas evangélicas, pentecostais e neopentecostais entre os povos indígenas no Brasil, Universidade Estadual de Campinas, Campinas, pp. 169-198. 2006, Aspectos fundamentais da cultura kaingang, Curt Nimuendajú, Campinas.

Vilaça, Aparecida y Robin Wright (eds.), 2009, Native Christians: Modes and Effects of Christianity among Indigenous Peoples of the Americas, Ashgate, Farnham.

Wiik, Flávio Braune, 2004a, Christianity Converted: An Ethnography Analisis of The Xokleng Laklanõ Indians and the Transformations Resulting from their Encounter with Pentecostalism, tesis de doctorado en antropología social, Universidad de Chicago, Chicago.

,2004b, "O evangelho transformado: apropriações xokleng (jê) do cristianismo pentecostal", en Robin Wright (ed.), Transformando os deuses, vol. 2: Igrejas evangélicas, pentecostais e neopentecostais entre os povos indígenas no Brasil, Universidade Estadual de Campinas, Campinas, pp. 141-168.

Wright, Robin, 1999, “O tempo de Sophie: história e cosmologia da conversão baniwa”, en Robin Wright (ed.), Transformando os deuses, vol. 1: Os múltiplos sentidos da conversão entre os povos indigenas no Brasil, Universidade Estadual de Campinas, Campinas, pp. 155-216.

\section{Entrevistas}

Luciana, Terra Indígena Xapecó, Santa Catarina, 18 de diciembre de 2013. Arlete, Xanxerê, Santa Catarina, 20 de diciembre de 2013. 